\title{
Towards the 3-D microfabrication and integration of a complete power unit used for energy autonomous wireless system
}

\author{
Tristan Pichonat ${ }^{\mathrm{a}, \mathrm{b}}$, Christophe Lethien ${ }^{\mathrm{a}, \mathrm{b}}$, Djamila Hourlier ${ }^{\mathrm{a}}$, Nicolas Tiercelin ${ }^{\mathrm{a}}$, David \\ Troadec $^{\mathrm{a}}$, and Paul-Alain Rolland ${ }^{\mathrm{a}, \mathrm{b}}$

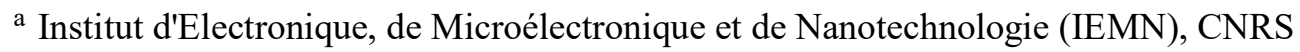 \\ UMR 8520, BP 60069, 59652 Villeneuve d'Ascq cedex, FR \\ ${ }^{\mathrm{b}}$ Institut de Recherche sur les Composants logiciels et matériels pour l'Information et la \\ Communication Avancée (IRCICA), CNRS FR 3024, \\ 50 avenue Halley, 59650 Villeneuve d'Ascq, FR
}

\begin{abstract}
This paper deals with the fabrication of an all-solid lithium-ion microbattery for autonomous wireless sensors networks nodes, focusing especially on the solid electrolyte and the negative electrode made of silicon nanowires. Regarding the electrolyte, amorphous thin solid films of lithium phosphorus oxynitride (LiPON) were prepared by radio-frequency sputtering of a mixture target of $\mathrm{P}_{2} \mathrm{O}_{5}-\mathrm{Li}_{2} \mathrm{O}$ in ambient nitrogen atmosphere. The morphology, composition, and ionic conductivity were characterized by X-ray diffraction, energy dispersive X-ray spectroscopy, X-ray photoelectron spectroscopy, and A.C. impedance spectroscopy. A microstructuring process is proposed, including a double masking with silicon oxide and silicon nitride layers. Finally, the combination of silicon nanowires and LiPON is presented.
\end{abstract}

\section{Introduction}

As wireless sensor applications and installations continue to grow just as the concept of smart environments, the way to autonomous power supply is more than ever one of the key factors (1) to lean towards autonomous and self organizing wireless sensor networks (WSN) (fig.1). To comply with autonomous and miniaturization concepts, the WSN node (fig. 2) has to include a small power unit mainly composed of three parts, namely the energy harvesting system, the energy storage device, and the energy management subsytem. The ultimate goal of our current research is to provide miniaturized and integrated autonomous power supply for WSN nodes, especially for the supply of both the management module and the low consumption wireless communication transceivers. According to the relative low power consumption of the wireless module designed in our group (target consumption: $100 \mu \mathrm{W})$, the short radiofrequency range $(10 \mathrm{~m})$ mainly due to the operating carrier frequency (millimetre wave: $60 \mathrm{GHz}$ ) and the low data rate transmission of such WSN (several bits/s), it is expected to develop a small energy device integrated in a volume close to a few cubic centimetres $\left(\sim \mathrm{cm}^{3}\right)$ in order to provide a low cost, small size, robust and packaged node. 
To follow the specifications previously described, effort is notably put on the storage unit with the fabrication of an all-solid-state thin film lithium-ion (Li-ion) microbattery on a glass substrate.

This study especially focuses on the 3-D microstructuration of a solid electrolyte as well as its combination with silicon nanowires as the anode of the microbattery. Combining the advantages of silicon material such as its low cost, a high specific insertion capacity (up to 4.4 lithium per silicon), a high theoretical capacity (4200 mAh. $\left.\mathrm{g}^{-1}\right)$, and the advantages of nanowires for battery electrode applications (large surface to volume ratio, efficient 1-D electron conducting pathways, accomodation of the volumic expansion associated with the lithiation/delithiation during the charge/discharge of the battery), silicon nanowires are currently one of the emerging solutions that could potentially replace carbonaceous materials (2-4). A complete structure of the battery is sketched in fig. 3. Miniaturization can be achieved through the use of micro- and nano-technology facilities, particularly used in the fields of microelectronics and MEMS fabrication. Solid-state vacuum-sputtered Lithium Phosphorous Oxynitride (LiPON) was chosen as the solid electrolyte. Even if LiPON material has been extensively investigated over the last 15 years (5-9), micropatterning is still a challenge $(10,11)$. The physicochemical characterization of the LiPON layer has been performed (XPS, XRD, EDX), as well as AC impedance spectroscopy to exhibit the ionic conductivity of the solid electrolyte. This study also gives a way for structuring LiPON films through dry and wet chemical etching processes. Moreover, as mentioned above, silicon nanowires were associated to the LiPON layer electrolyte in order to provide the negative electrode of the microbattery. One of the many challenges of this study is to provide a technological process allowing the electrical connection between all the nanowires on an insulating glass substrate, contrary to the common use of stainless steel substrates in battery fabrication $(2,3)$.

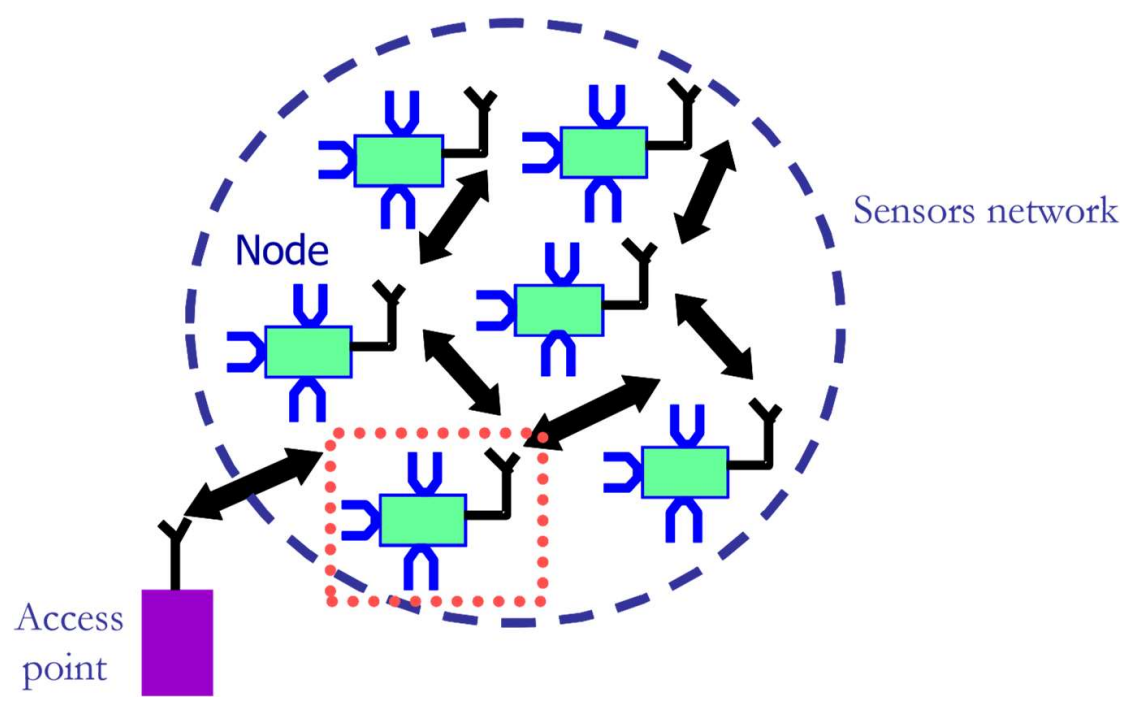

Figure 1. Schematic approach of a wireless sensors network. 


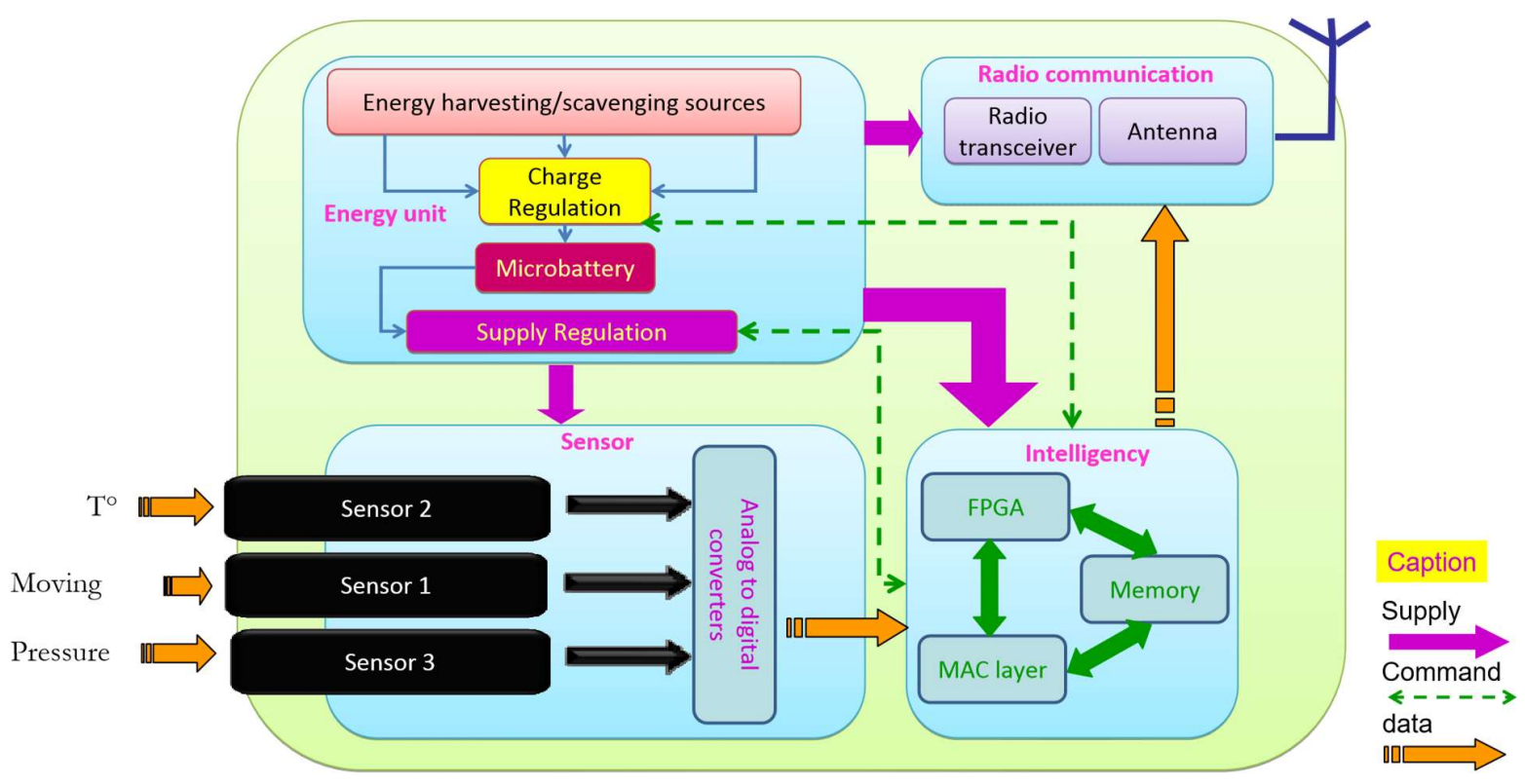

Figure 2. Details of one node from a WSN.

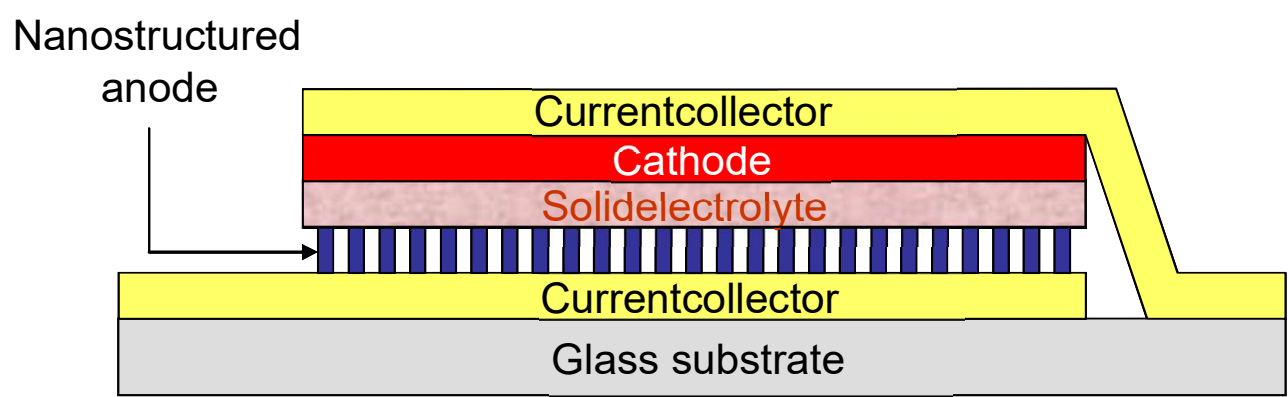

Figure 3. Sktech of the complete battery structure.

\section{Experimental details}

Nanowires growth

A $500 \mathrm{~nm}$-thick n-doped $\left(10^{18} \mathrm{~cm}^{-3}\right)$ polycrystalline silicon layer is first deposited by low pressure chemical vapor deposition (LPCVD) at $700^{\circ} \mathrm{C}$ on a glass substrate. This material will be used as a contact layer to gather the electronic contributions of each nanowire. A $10 \mathrm{~nm}$-thick gold layer is evaporated and structured through a standard lifoff process on the polycrystalline silicon layer. Gold is used as the metal catalyst for $\mathrm{Si}$ nanowires growth. The silicon nanowires ( $\mathrm{SiNW}$ ) are then traditionally grown under $\mathrm{SiH}_{4}$ atmosphere through a vapor liquid solid CVD process (2). 
LiPON thin film electrolyte is deposited over the nanowires by a radiofrequency sputtering of a 4-inch mixture target of $\mathrm{P}_{2} \mathrm{O}_{5}-\mathrm{Li}_{2} \mathrm{O}(0.25: 0.75)$ prepared by Super Conductor Materials, Inc. The target material was sputtered in a Leybold Z550 equipment after pumping down to a base vacuum of $10^{-4} \mathrm{~Pa}$. A diode RF-sputtering was used at $13.56 \mathrm{MHz}$ with a constant forward power of $3.7 \mathrm{~W} . \mathrm{cm}^{-2}$ in a pure nitrogen atmosphere $\left(\mathrm{N}_{2}\right)$ and at a pressure of $0.6 \mathrm{~Pa}$.

For the AC impedance measurements, a LiPON layer is deposited between two 500 nm-thick layers of Cr-Pt elaborated by evaporation within the same conditions than previously described.

Fig. 4 displays the structuring process of the LiPON layer. It includes the deposition of silicon nitride and silicon oxide masking layers by a PECVD low temperature process $\left(100^{\circ} \mathrm{C}\right)$. Further details will be given in the next section.
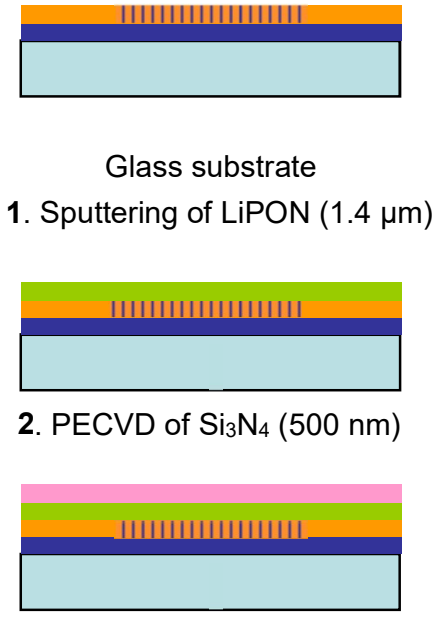

3. PECVD of $\mathrm{SiO}_{2}(600 \mathrm{~nm})$

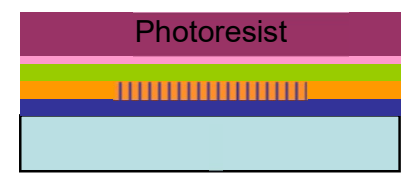

4. Spin-coating of photoresist

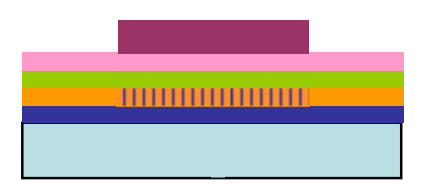

5. Photolithography

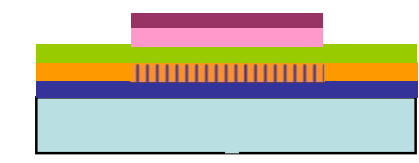

6. $\mathrm{CF}_{4} / \mathrm{CHF}_{3}$ reactive ion etching of $\mathrm{SiO}_{2}$ film

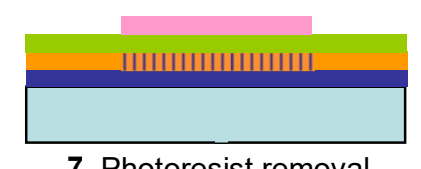

7. Photoresist removal

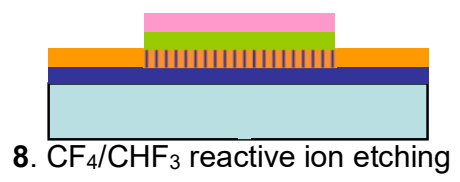

of $\mathrm{Si}_{3} \mathrm{~N}_{4}$ film

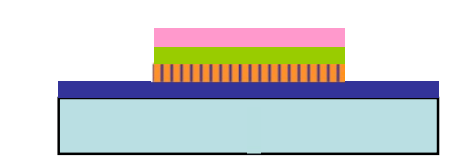

9. Wet etching of LiPON (diluted solution of TMAH)
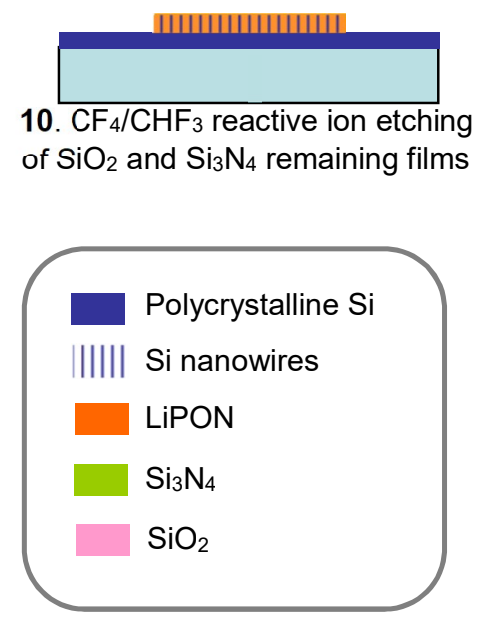

Figure 4. Diagram of the complete LiPON microstructuring process.

\section{Characterization}

The thickness of the films was determined using surface profilometer (Dektak II a) and SEM (Zeiss Ultra 55) / FIB (FEI Strata DB 235) imaging. Bruker D8 Advance X-ray diffractometer (XRD) was used to define the nature of the films (crystalline or amorphous). The composition was measured with X-ray photoelectron spectroscopy (XPS, instrumentation based on a Physical Electronics 5600 model) and energy dispersive X-ray spectroscopy (EDX, Xflash 4010 system from Bruker AXS). XPS measurements were performed with a monochromatic $\mathrm{Al} \mathrm{K} \alpha$ x-ray source $(1486.6 \mathrm{eV})$ and an analyzer pass 
energy of $12 \mathrm{eV}$. The intensities of core levels of O 1s, Li 1s, P 2p and N 1s were measured as the peaks areas after standard background substraction according to Shirley procedure.

The ionic conductivity of the films was determined through AC impedance spectroscopy (Solartron SI 1260) with Cr-Pt | LiPON | Cr-Pt sandwich structures on glass substrates over a frequency range of $10 \mathrm{~Hz}$ to $3 \cdot 10^{7} \mathrm{~Hz}$. The considered area of the electrodes was $1 \mathrm{~cm}^{2}$.

\section{Results and discussion}

\section{$\underline{\text { Silicon nanowires }}$}

In situ n-doped SiNW of 400-nm diameter were obtained on the polysilicon layer. A resistivity of $10^{-2} \Omega . \mathrm{cm}$ was previously measured for the polysilicon layer thanks to fourprobe V(I) measurements. The aspect of the obtained SiNW is observed on fig. 5. Actually, at this stage, accent was not put on the size nor the density of the SiNW, but rather on how the LiPON electrolyte was going to deposit on them.

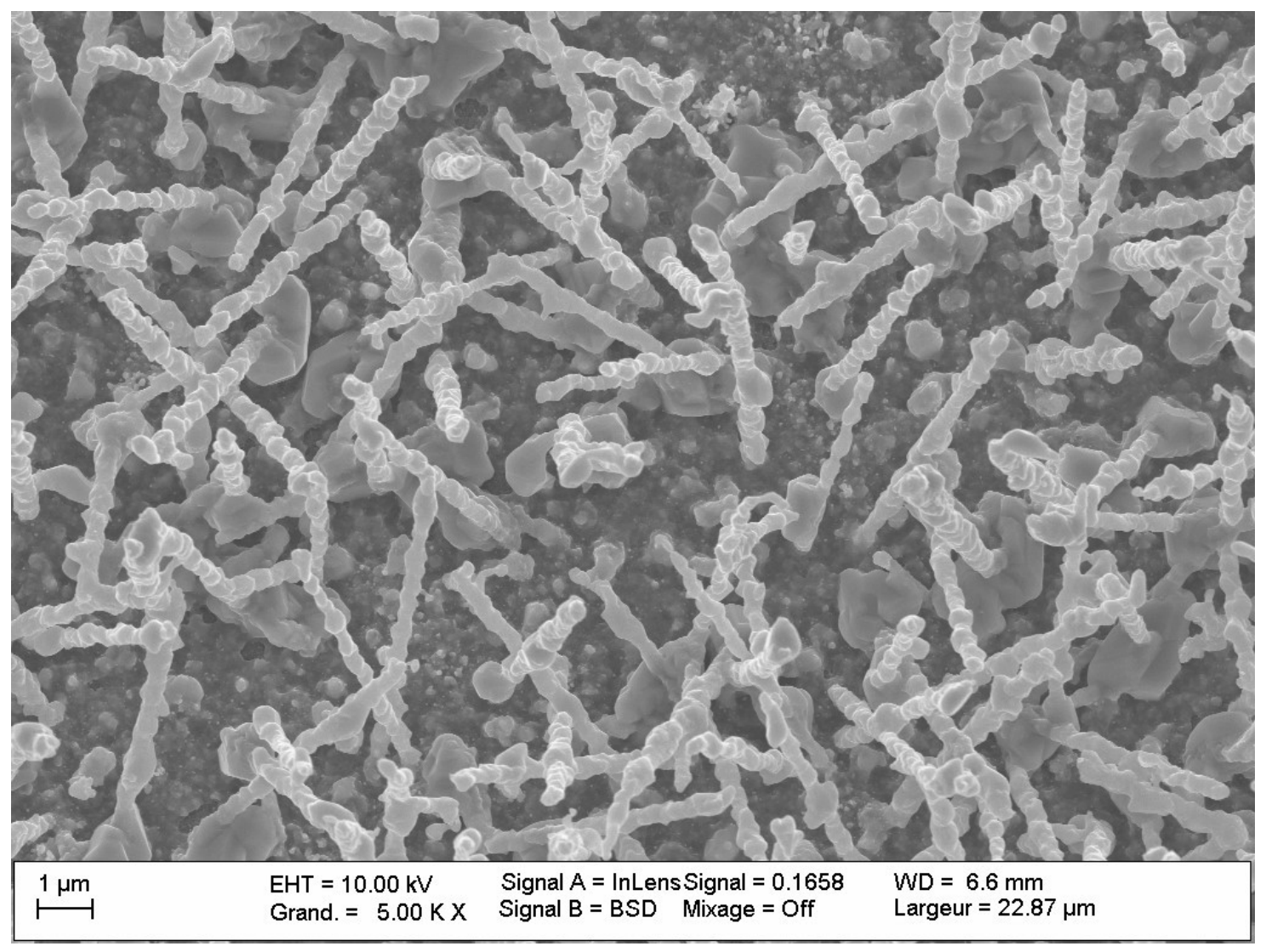

Figure 5. SEM front view of the silicon nanowires grown on polycrystalline silicon. 


\section{LiPON electrolyte}

First step was to confirm the quality of the LiPON films, i.e. to show the conformity of the sputtered layers with the literature, as well as to bring further results.

Morphological aspects. XRD was performed on a multilayer composed from bottom to top of $\mathrm{Cr}(100 \mathrm{~nm}), \mathrm{Pt}(100 \mathrm{~nm})$, and LiPON $(1.4 \mu \mathrm{m})$. No sharp diffraction peaks appear in the XRD pattern (Fig. 6a) except those attributed to underlying $\mathrm{Pt}\left(40^{\circ}, 46^{\circ}\right.$, and $\left.68^{\circ}\right)$ and $\mathrm{Cr}\left(44^{\circ}\right)$. A broad peak from 15 to $40^{\circ}$ such as the ones observed in $(5,13)$ suggests that the deposited LiPON electrolyte exhibits an expected amorphous structure, contrary to the $\mathrm{P}_{2} \mathrm{O}_{5}-\mathrm{Li}_{2} \mathrm{O}$ powder from the target which clearly exhibits the pattern of a crystallized material (Fig. 6b).

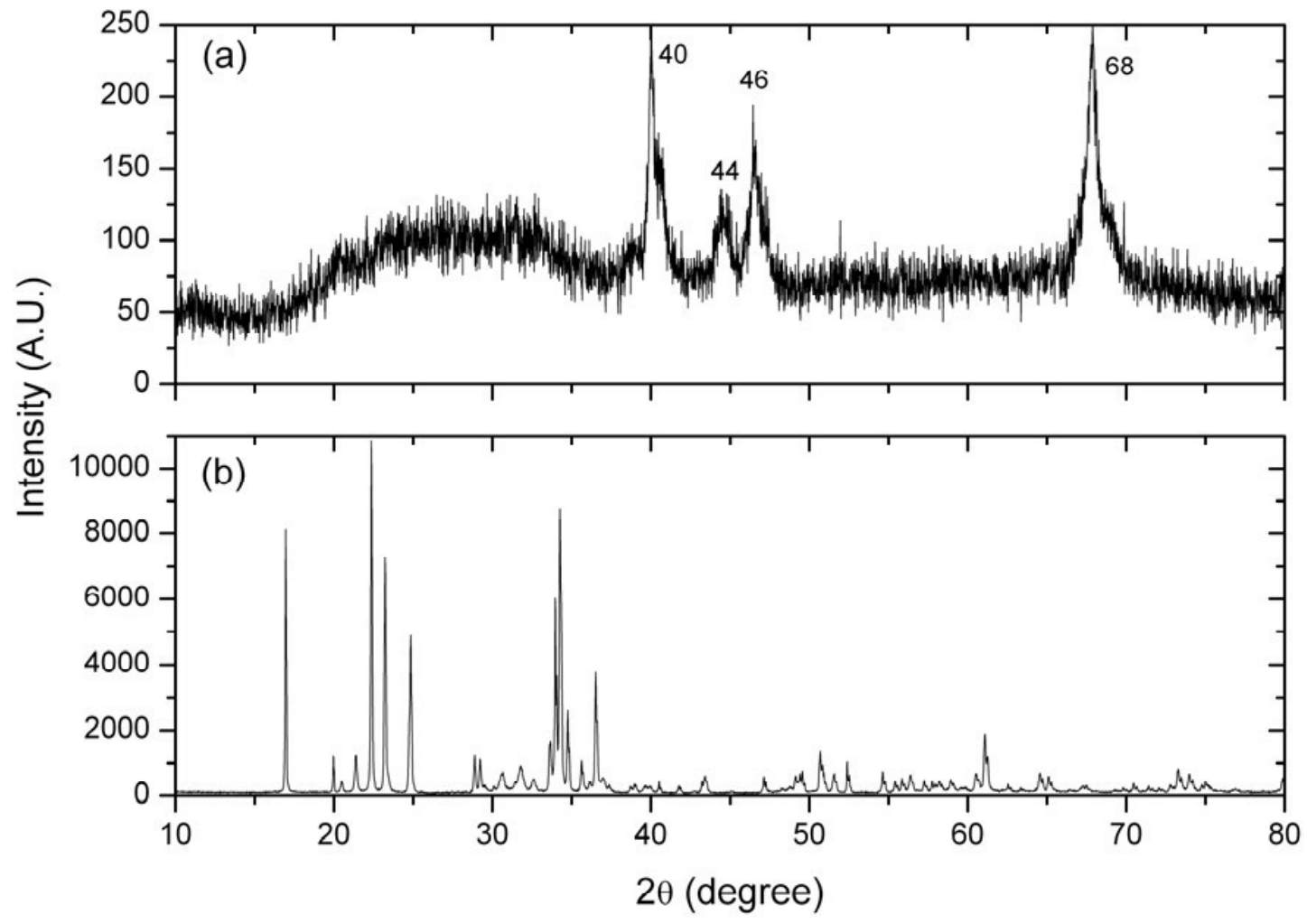

Figure 6. XRD patterns of the deposited $1.4 \mu \mathrm{m}$-thick LiPON thin film on Cr-Pt layer (a) and of the $\mathrm{P}_{2} \mathrm{O}_{5}-\mathrm{Li}_{2} \mathrm{O}(0.25: 0.75)$ mixture target powder (b). The four sharp peaks in (a) are identified as underlying $\mathrm{Pt}\left(40,46\right.$ and $\left.68^{\circ}\right)$ and $\mathrm{Cr}\left(44^{\circ}\right)$.

Thin film composition. EDX and XPS analyses were performed on the LiPON films with Cr-Pt as the underlying layer. EDX technique can not detect the lightest elements such as Li but enables to quantify the other components $(\mathrm{P}, \mathrm{O}, \mathrm{N})$ of the films and therefore to deduce the ratios between atoms (N/P and O/P). XPS analysis on the same samples has also demonstrated the appearance of the main peaks representative of the LiPON signature $(\mathrm{Li}$, $\mathrm{P}, \mathrm{O}, \mathrm{N}$ peaks). 
Results obtained from both EDX and XPS confirmed the presence and incorporation of nitrogen into the film in the proportions $\mathrm{N} / \mathrm{P}$ and $\mathrm{O} / \mathrm{P}$ respectively at 1.2 and 2.4, close to those measured by Hamon (6) and $\mathrm{Hu}(7)$ in similar conditions. XPS analysis also provides information about elemental bonding environments. Nitrogen $1 \mathrm{~s}$ core level has been decomposed into 3 Gaussian-Lorentzian mixed components, at 399, 400.5, and $405.5 \mathrm{eV}$ (Fig. 7), corresponding respectively to $\mathrm{P}-\mathrm{N}=\mathrm{P}, \mathrm{P}-\mathrm{N}<{ }_{\mathrm{P}}$ and $\mathrm{O}-\mathrm{N}=\mathrm{O}$ bondings. A good agreement with previous studies $(5,6,9)$ is found.

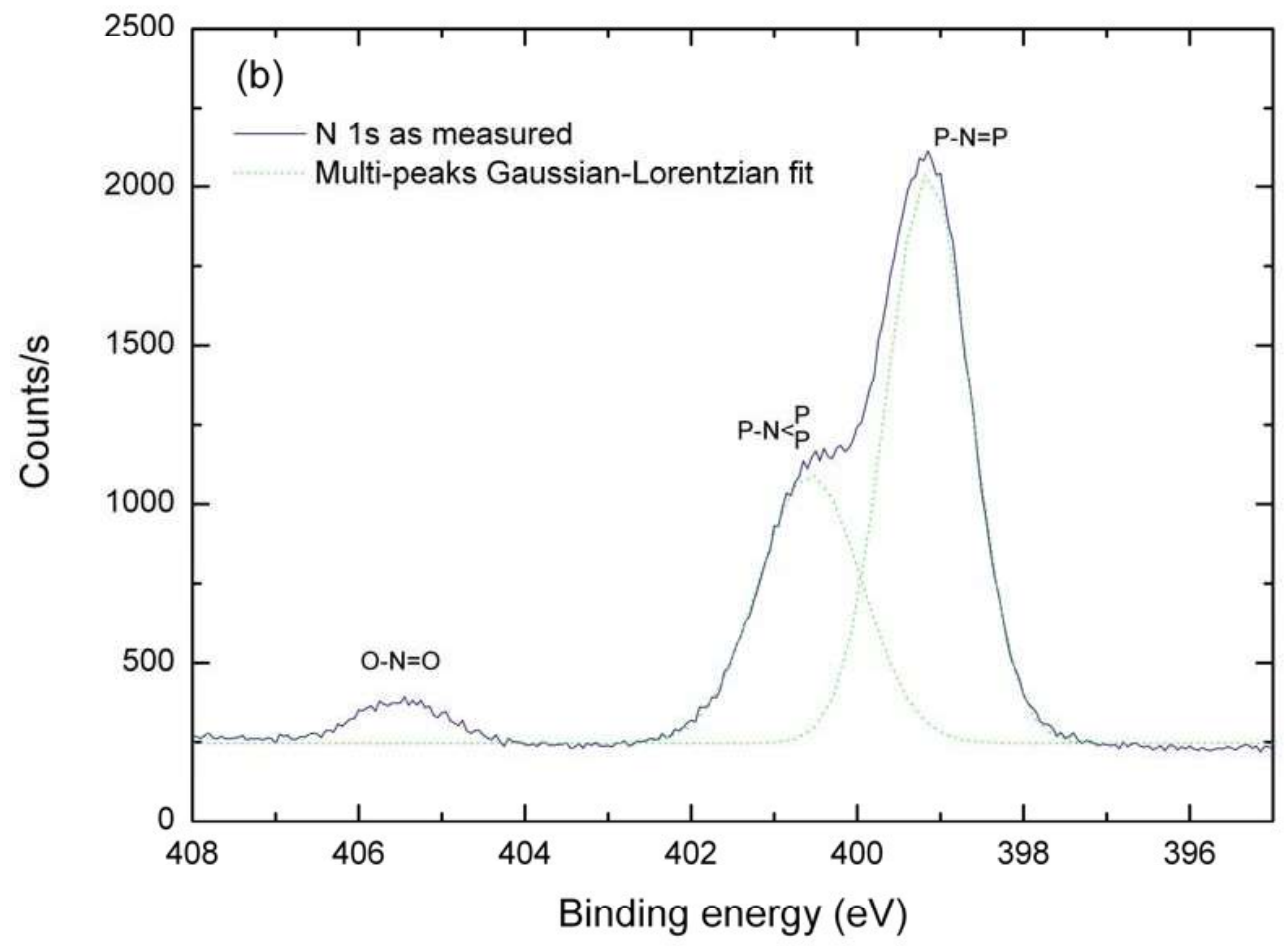

Figure 7. XPS spectrum of the deposited $1.4 \mu \mathrm{m}$-thick LiPON thin film on Cr-Pt layer in the region of the $\mathrm{N} 1 \mathrm{~s}$ peaks (406-395 $\mathrm{eV}$ range).

Ionic conductivity. The fig. 8 depicts the AC impedance spectroscopy measurement performed on the $1.4 \mu \mathrm{m}$-thick $\mathrm{Cr}-\mathrm{Pt}$ | LiPON | Cr-Pt sandwich structure at room temperature. The semi-circle diameter is correlated to the resistance value of the LiPON layer (local minimum of -Z") allowing to exhibit the ionic conductivity of the solid electrolyte. Regarding to the electrode area $\left(\# 1 \mathrm{~cm}^{2}\right)$, the LiPON thickness and the measured electrolyte resistance, the ionic conductivity of the thin film is close to $6.10^{-7}$ ${\mathrm{S} . \mathrm{cm}^{-1}}^{-1}$ and so in relative good agreement (albeit lower) with previously reported values (59). 


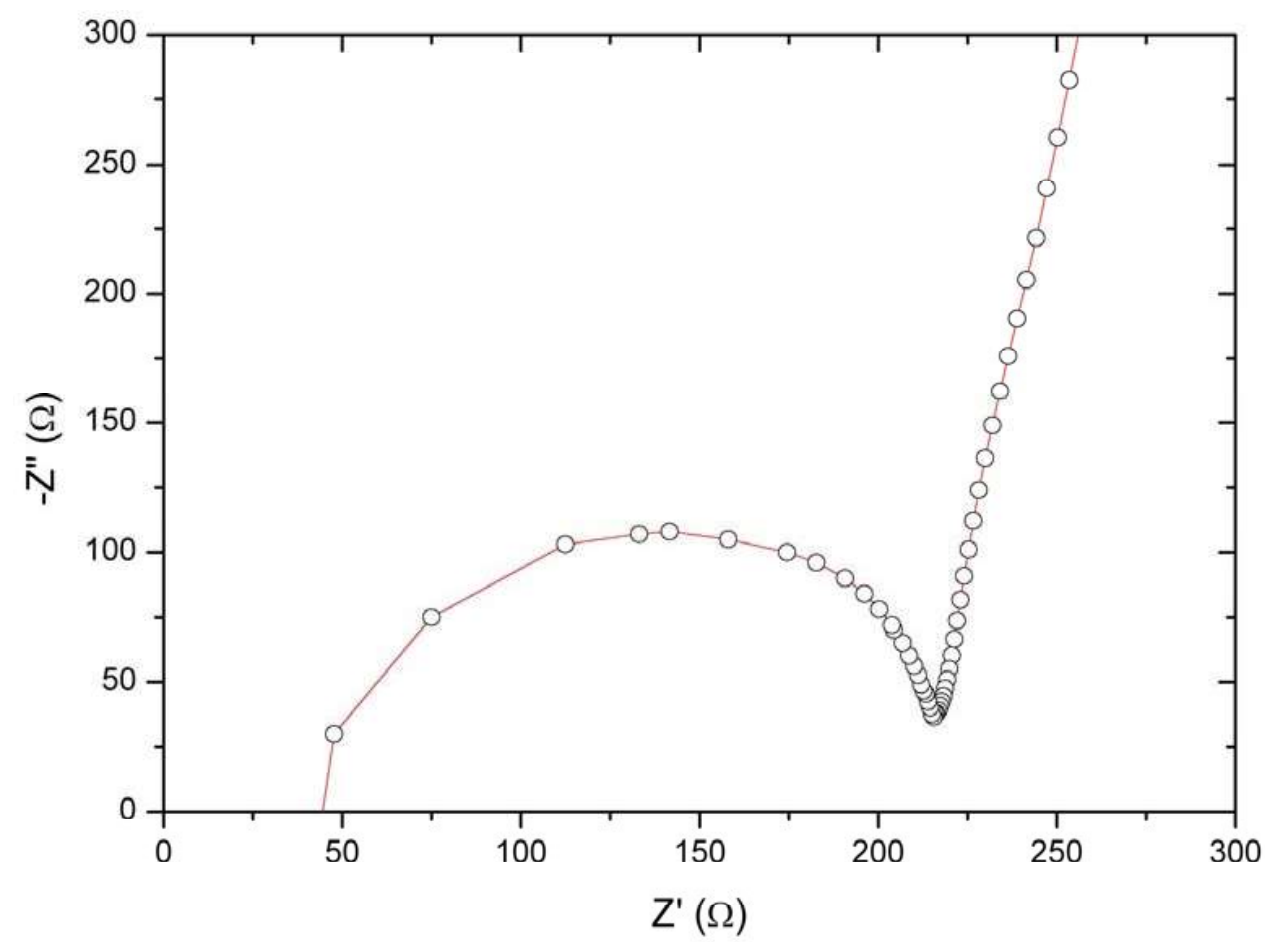

Figure 8. Nyquist AC impedance plot of the Cr-Pt|LiPON|Cr-Pt stack at room temperature.

\section{$\underline{\text { LiPON depositing on silicon nanowires }}$}

A $1.4 \mu \mathrm{m}$ thick LiPON layer was sputter-deposited onto the nanowires (step 1 of the process presented in fig. 4). Results are displayed in fig. 9. These SEM pictures clearly show the complete coating of the nanowires by the LiPON layer. This is really important that it covers completely all the nanowires in order to avoid any possible short circuit with the future additional cathode layer that will be deposited over.

Other views of the coated SiNW were provided after vertical (fig. 10a) and horizontal (fig. 10b) cross-sections performed with a focus ion beam (FIB) device. They allow to show how the LiPON surrounds the nanowires. Because of the dielectric nature of the the LiPON layer, a thin FIB-sputterred layer of Pt had to be deposited over in order to practically make the cross-section possible without dissolving the LiPON layer with the ion beam. 


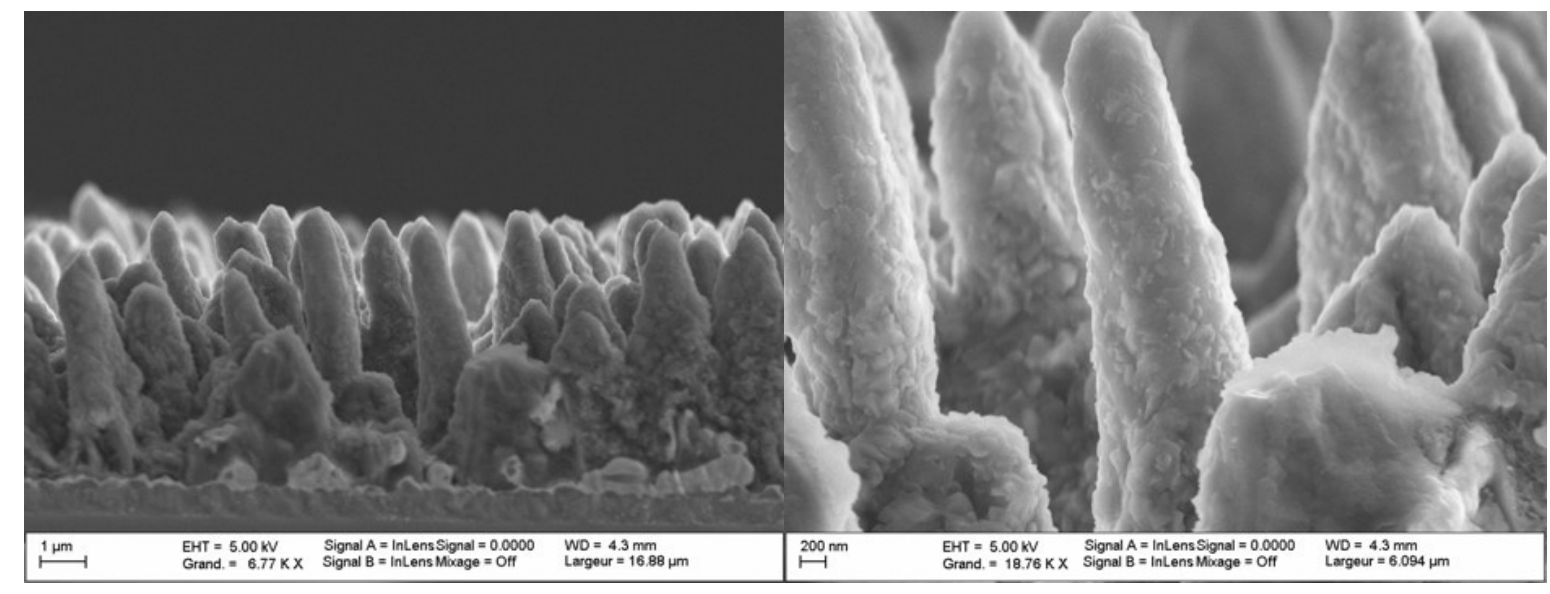

Figure 9. SEM cross section views of LiPON coated silicon nanowires.

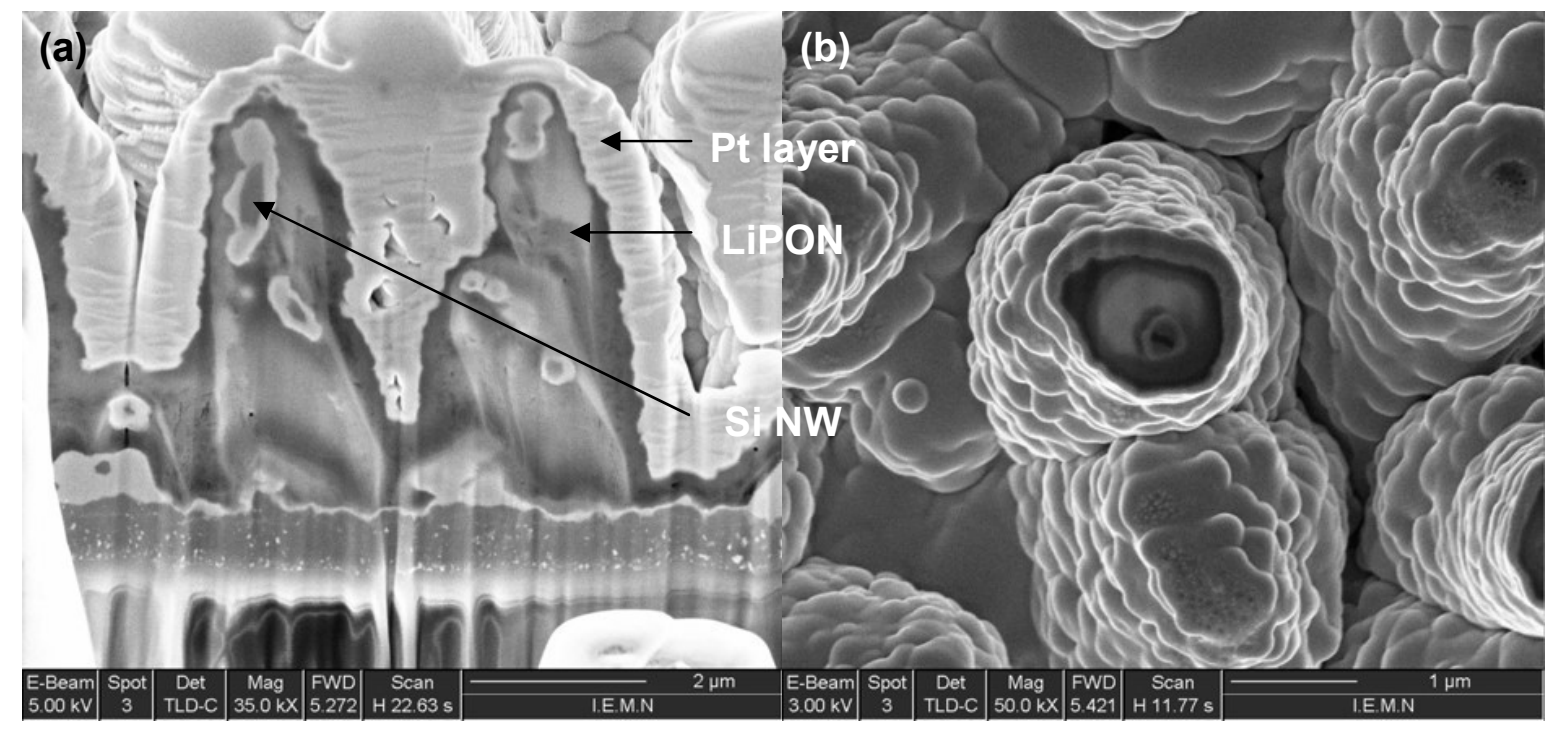

Figure 10. SEM views of FIB cross section LiPON coated silicon nanowires. (a) vertical cross section and (b) horizontal cross section.

Microstructuring. The miniaturization of the battery part goes through the structuring of the different layers, and notably the LiPON layer. An etching process of the LiPON thin film was developped in order to structure the layer. Problem with LiPON is that it can be etched by the majority of the optical photoresist developpers usually based on diluted hydroxide weak bases such as tetramethyl ammonium hydroxide (TMAH), or potassium hydroxide $(\mathrm{KOH})$, and sometimes more quickly than the photoresist itself. So the main challenge was structuring it without removing it entirely. The process diagram is displayed in fig. 4. A double mask made of PECVD layers of low temperature silicon nitride ( $\mathrm{SiN}$ ) and silicon oxide $\left(\mathrm{SiO}_{2}\right)$ was used. This double masking is necessary to protect efficiently the LiPON layer from the photolithograpy step. Silicon nitride allows not to oxidize the LiPON layer. Low temperature deposition processes (about $100{ }^{\circ} \mathrm{C}$ ) were conducted to keep the amorphous integrity of the LiPON layer. As soon as these layers are covering the LiPON layer, then the photolithography with standard optical photoresist can be performed. The $\mathrm{SiO}_{2}$ layer is etched by reactive ion etching (RIE) through a standard process with 
fluoride gases. The remaining photoresist is then removed by RIE or by wet etching. The $\mathrm{SiN}$ layer is etched through the same RIE process than the $\mathrm{SiO}_{2}$ layer. The $\mathrm{LiPON}$ layer can then be etched in a diluted solution of TMAH. The remaining $\mathrm{SiO}_{2}$ and $\mathrm{SiN}$ films are eventually removed with the same previously performed RIE fluoride process.

\section{Conclusion}

With the final aim of powering autonomous wireless sensors networks nodes, we have first put efforts on the energy storage part, constituted by a Li-ion microbattery. We have achieved the sputter deposition of thin LiPON electrolyte films with similar characteristics than previous literature. Time was especially devoted to the material characterization, as one of the keypoint for the development of efficient batteries. A process for microstructuring the LiPON layer was proposed, and further results will soon be published. Wishing to use silicon nanowires as negative electrode for the microbattery, the complete coating of the nanowires with LiPON was performed.

\section{Acknowledgments}

This work was supported by the ERDF (European Regional Development Fund) and by the Nord-Pas-de-Calais Region (France). The authors want to thank C. Boyaval (IEMN) for the EDX studies, S. Godey (IEMN) for the XPS studies, Pascal Roussel, Marie Colmont, and E. Capoen (UCCS, CNRS UMR 8181, Villeneuve d'Ascq, France) for both the XRD studies and their help on impedance spectrometry measurements.

\section{References}

1. F.L. Lewis, in: Smart environments: technologies, protocols, and applications, ed. D.J. Cook and S.K. Das, John Wiley, New York (2004).

2. B. Laïk, L. Eude, J.-P. Pereira-Ramos, C. S. Cojocaru, D. Pribat and E. Rouvière, Electrochimica Acta Vol. 53 (17), 5528-5532 (2008).

3. C. K. Chan, H. Peng, G. Liu, K. McIlwrath, X. F. Zhang, R. A. Huggins, Y. Cui, Nature Nanotech. 3, 31-35 (2008).

4. K. Peng, J. Jie, W. Zhang, S.-T. Lee, App. Phys. Lett. 93, 033105 (2008).

5. J.B. Bates, N.J. Dudney, G.R. Gruzalski, R.A. Zhur, A. Choudhury, C.F. Luck and J. Robertson, J. Power Sources 43, 103-110 (1993).

6. N.-S. Roh, S.-D. Lee, H.-S. Kwon, Scripta Mater. 42 (2000) 43-49.

7. C. Choi, W. Cho, B. Cho, H. Kim, Y. Yoon, Y. Tak, Electrochemical and Solid- State Letters 5 (2002) (1) A14-A17.

8. Y. Hamon, Ph.D. thesis report, Université de Bordeaux 1 (2004). URL: http://tel.archivesouvertes.fr/docs/00/04/72/38/PDF/tel-00007239.pdf

9. Z. Hu, D. Li, K. Xie, Bull. Mater. Sci. 31 (2008) (4) 681-686.

10. S. Oukassi, X. Gagnard, R. Salot, S. Bancel and J.P. Pereira-Ramos, in: Proc. of Design, Test, Integration, and Packaging of MEMS and MOEMS (DTIP), Stresa, Italy, 26-28 april 2006.

11. J. Song, X. Yang, S.-S. Zeng, M.-Z. Cai, L.-T. Zhang, Q.-F. Dong, M.-S. Zheng, S.-T.Wub and Q.-H. Wu, J. Micromech. Microeng. 19 (2009).

12. W.-Y. Liu, Z.-W. Fu, C.-L. Li, Q.-Z. Qin, Electrochem. Solid-State Lett. 7 (9) J36-J40 (2004).

13. K. Chung, W.-S.Kim, Y.-K. Choi, J. Electroanalytical Chem. 566, 263-267 (2004). 